\title{
Chemical food safety of using former foodstuffs for rearing black soldier fly larvae (Hermetia illucens) for feed and food use
}

\author{
H.J. van der Fels-Klerx ${ }^{1,2 *}$, N. Meijer ${ }^{1}$, M.M. Nijkamp ${ }^{1}$, E. Schmitt ${ }^{3}$ and J.J.A. van Loon ${ }^{4}$ \\ ${ }^{1}$ Wageningen Food Safety Research, Akkermaalsbos 2, 6708 WB, Wageningen, the Netherlands; ${ }^{2}$ Business Economics Group, \\ Wageningen University, Hollandseweg 1, 6706 KN, Wageningen, the Netherlands; ${ }^{3}$ Protix B.V., Industriestraat 3, Dongen \\ 5107 NC, the Netherlands; ${ }^{4}$ Wageningen University, Department of Plant Sciences, Laboratory of Entomology, Wageningen, \\ the Netherlands; ine.vanderfels@wur.nl
}

Received: 3 April 2020 / Accepted: 14 May 2020

(C) 2020 Wageningen Academic Publishers

OPEN ACCESS CC)

\begin{abstract}
Black soldier fly (BSF, Hermetia illucens) larvae is considered one of the insect species with great potential for large-scale production as feed and food. For this to become economically feasible and to contribute to a circular economy, BSF larvae should be reared on substrates with little or no alternative use for feed and food production. One such class of alternative substrate sources consists of former food products. However, BSF larvae may accumulate chemical contaminants from the substrate, which may originate from the foodstuff and/or the packaging materials. This study aimed to investigate the possible presence of chemical contaminants in BSF larvae being reared on former foodstuff substrates at both laboratory and industrial scale. Four experimental treatments were set up: with meat or vegetarian, and containing between 3-6\% of either plastic or paperboard carton packaging material. Four-day old BSF larvae were reared for seven days on these substrates. Concentrations of heavy metals, mineral oil hydrocarbons, dioxins and PCBs, and polycyclic aromatic hydrocarbons were determined in the substrate, residual material, and the larvae. Results suggest that BSF larvae can be reared on former food products containing traces of packaging materials, without negative effects on their growth or survival. Bio-accumulation was observed for most of the tested contaminants, in particular for mineral oils and cadmium, which had a bio-accumulation rate of, respectively, about five and 20. However, none of the concentrations of the analysed contaminants in the substrate and the larvae exceeded the respective legal limits in the EU. Results of this pilot study were promising. As a next step, more different former food products should be investigated in future research.
\end{abstract}

Keywords: contaminants, accumulation, packaging materials, circularity, supermarket returns

\section{Introduction}

Insects are considered an alternative source of proteins for feed and food production in Europe, in particular for partially replacing or supplementing traditional protein sources such as maize gluten meal (Van Raamsdonk et al., 2017). The black soldier fly (BSF, Hermetia illucens L.; Diptera: Stratiomyidae) is considered one of the insect species with great potential for large-scale production as a feed and food ingredient (Nguyen et al., 2015). BSF larvae have a high nutritional value, and low emission of greenhouse gases and ammonia (Barragan-Fonseca et al., 2017; Ermolaev et al., 2019; Mertenat et al., 2019).
Currently, BSF larvae are reared on substrates that could also be used as feed materials for production animals (Wang and Shelomi, 2017). For production of large quantities of BSF larvae to become economically feasible and to contribute to circular economy, they should be reared on substrates with little or no alternative use for feed and food production (Smetana et al., 2016, 2019). Indeed, BSF larvae are well able to convert organic waste (Bosch et al., 2019; Jozefiak et al., 2016; Schmitt et al., 2019). The larvae have a high growth rate at environmental temperatures of $20-30{ }^{\circ} \mathrm{C}$ on various decaying organic materials, e.g. from rotting fruits and vegetables, to household waste, supermarket/catering returns and animal manure and 
human excreta (Lähteenmaki-Utela et al., 2017). Of these alternative substrates, plant-derived materials and former foodstuffs without meat and fish are the two types that are (currently) legally allowed in the European Union and, therefore, the preferred substrate options on the short term. Former foodstuffs are considered food products for human consumption that are no longer intended for human consumption due to reasons such as expired use-by date or due to problems of manufacturing or packaging defects (point 3, Part A, Annex to Regulation (EU) No 68/2013; EC, 2013).

Before introduction as a feed or food product or ingredient on the European market, the safety of BSF larvae to animal and human health should be ensured. Quite some research has been performed on the safety of rearing BSF larvae for feed and food production in recent years, but many facets are still unknown. Recently, data became available from surveys (Charlton et al., 2015) and from controlled experiments on substrates spiked with heavy metals (Diener et al., 2015; Van der Fels-Klerx et al., 2016) and mycotoxins (Bosch et al., 2017; Camenzuli et al., 2018; Van Broekhoven et al., 2017). However, to date, no such safety data are available specifically for using former foodstuffs as substrate for BSF rearing. In principle, former foodstuffs are food grade and little food safety concerns are to be expected. However, traces of packaging materials may remain in former food products that have been mechanically processed to be used as feed (Van Raamsdonk et al., 2011). Packaging materials are prohibited for animal nutrition purposes (Annex III of Regulation (EC) No. 767/2009; EC, 2009). However, 'European Union Member States generally agree that a zero tolerance for these traces is neither practical, nor proportionate to the risk' (ACAF, 2013). As such, the United Kingdom (UK), Germany, and the Netherlands have established a tolerance limit of $0.15 \%$ (ACAF, 2013). Furthermore, insects may differ in their accumulation or excretion patterns of chemical contaminants, as compared to traditional production animals. BSF larvae, for instance, were found to accumulate cadmium (Cd) up to $9.5 \pm 3.6$ times when reared on concentrations equal to 0.5 times the EU legal limit $(0.25 \mathrm{mg} / \mathrm{kg}$ ) (Van der Fels-Klerx et al., 2016). Therefore, possible accumulation of chemical contaminants in BSF larvae reared on former foodstuffs should be investigated in more detail. We hypothesised that accumulation patterns in BSF larvae differed depending on whether the substrate contained meat or not, and depending on the type of packaging material, i.e. plastic or paperboard carton. This study aimed to investigate the possible presence of chemical contaminants in BSF larvae being reared on former foodstuff based substrates.

\section{Methods and materials}

A controlled experiment was performed at laboratory scale, and a validation trial was held at industrial scale. The small-scale experiment (SSE) was performed at the Laboratory of Entomology of Wageningen University, the Netherlands. The large-scale experiment (LSE) was held at Protix BV, in Dongen, the Netherlands. Samples were chemically analysed at Wageningen Food Safety Research (WFSR), Wageningen, the Netherlands.

\section{Insects}

For the SSE, BSF eggs were obtained from a continuous stock colony maintained at constant conditions in a climate room $\left(27 \pm 1{ }^{\circ} \mathrm{C}, 70 \%\right.$ relative humidity, L12:D12) at the Laboratory of Entomology. For each experimental replicate, 300 larvae being four days old since hatching from the egg were counted and weighed at the beginning of the experiment. Larvae for the LSE were provided by Protix B.V. In the LSE, the numbers of larvae per replicate were estimated based on a smaller sample. Firstly, 3.0 grams of four-day old larvae and their substrate were counted. This sample contained 133 individuals. Mean individual larval weight was determined and used to calculate the required total larval weight per replicate, to have approximately 4,200 larvae per replicate.

\section{Experimental set-up}

Four experimental treatments were set up (Table 1): substrates with meat containing plastic (MP), vegetarian substrates (without meat) containing plastic (VP), substrates with meat containing carton $(\mathrm{MC})$ and vegetarian substrates containing paperboard carton (VC). In addition to the four experimental treatments, a control treatment (C) was included in both SSE and LSE. Each food product was unpacked, and then the food was shredded. The packaging material was shredded (separately) with a metal consumergrade scissor to a maximum particle size of $1.0 \mathrm{~cm}$. The food product was then mixed again with its shredded packaging material (see below).

Table 1. Schematic representation of experimental treatments: packaging material and primary former food product ingredient.

\begin{tabular}{lll} 
Former food stuff meal & \multicolumn{2}{l}{ Packaging material } \\
\cline { 2 - 3 } & Plastic & Paperboard carton \\
Meat & MP & MC \\
Vegetable & VP & VC
\end{tabular}


Each of the five treatments was assayed in triplicate during the SSE and in duplicate during the LSE. For all treatments in the SSE, for each replicate 300 BSF larvae of four days old were placed in a plastic container together with the experimental substrate. Dimensions of the container in the SSE were $17.8 \times 11.4 \times 6.5 \mathrm{~cm}$. These were plastic containers with transparent ventilated lids; ventilation occurred through textile (pieces of nylon panty hoses, 10 dernier, Hema, the Netherlands), covering openings cut in the lid of the container. In the LSE, approximately 4,200 BSF larvae of four days old were placed in a large industrial size plastic container with dimensions $40 \times 60 \times 12 \mathrm{~cm}$.

For the SSE, the containers were incubated in a climate chamber at $27{ }^{\circ} \mathrm{C}$ with $70 \%$ relative humidity and a photoperiod of $12 \mathrm{~h}$. In the LSE, the containers were incubated under the same conditions as with the SSE, but no specific photoperiod was established. BSF larvae were reared until the day the first pre-pupae were observed (day 6). Then, the larvae were taken out of the feed substrate in accordance with Oonincx et al. (2015), rinsed and dried, and subsequently placed in new empty containers for $24 \mathrm{~h}$ (the 'starvation period') before harvesting. The larvae per replicate in the SSE were counted on day 6 and 7. For both SSE and LSE, the BSF larvae were cleaned from the residual material by rinsing them in hand warm water and drying them using paper. The weight of the larvae were determined post-rinsing and drying. Larvae and the residual material (RM) samples were frozen at $-18{ }^{\circ} \mathrm{C}$.

\section{Substrates}

The four types of food products were bought in a local supermarket, including two different whole meals and two different types of snack products, both with paperboard carton and with plastic packaging materials. Sourcing from supermarkets rather than actual waste streams was preferred since it allowed for exact knowledge of the composition of the diets, even if they were later processed into a waste format before feeding. Details of the products are shown in Table S1 (SSE) and Table S2 (LSE) in the supplementary materials. The control feed in the SSE consisted of poultry feed ('Kuikenopfokmeel 1', Kasper Faunafood, Woerden, the Netherlands), and the control feed in the LSE consisted of a GMP + agricultural by-product (normally used for industrial BSF larvae rearing at Protix). In both SSE and LSE, a packaging inclusion rate higher than regulatory levels for animal feeds was used to provide a 'worst case' assessment of bioaccumulation of chemicals from substrate (with the packaging materials).

The wet weight of substrate in the SSE was determined by summing the weight of the fat, carbohydrates, fibre, protein, and salt - as based on the respective ingredient declarations. In both experiments, water was added to each of the replicate's containers in the MC and VC treatments, such that the initial water content of each substrate was $\sim 75 \%$. In the SSE, $50 \%$ of the substrate was provided on day (D) 1 , and the remaining $50 \%$ on D3 (Table 2). Corresponding volumes of water were added on D3 to again bring the water content of the substrate to $~ 75 \%$. In the LSE, $100 \%$ of the substrate was provided on D1. Approximately $35-40 \%$ of soya powder was added to the control substrate in the LSE following standard company procedures. In the SSE and the LSE, packaging materials (paperboard carton or plastic) were added such that the product contained a mean percent of either plastic or paperboard carton packaging material of between 3-6\%.

Table 2. Composition of feed substrate, water and packaging material provided to the larvae on day 1 (D1) and day 3 (D3) of the small- and large-scale experiments.

\begin{tabular}{|c|c|c|c|c|c|c|}
\hline Experiment & Treatment $^{1}$ & Substrate D1 (g) & Substrate D3 (g) & Water D1 (g) & Water D3 (g) & Packaging material D1 (g) \\
\hline \multirow{5}{*}{$\begin{array}{l}\text { Small-scale experiment } \\
\qquad(\mathrm{SSE})^{2}\end{array}$} & $\mathrm{C}$ & 28.4 & 28.5 & 50 & 59.1 & 0.0 \\
\hline & MC & 68.7 & 68.8 & 10 & 28.2 & 3.5 \\
\hline & VC & 58.7 & 58.6 & 10 & 41.3 & 3.6 \\
\hline & MP & 96.6 & 96.7 & 0 & 23.1 & 3.6 \\
\hline & VP & 85.9 & 85.9 & 0 & 0.0 & 3.5 \\
\hline \multirow{5}{*}{$\begin{array}{l}\text { Large-scale experiment } \\
\qquad(\mathrm{LSE})^{3}\end{array}$} & $\mathrm{C}$ & $1,989.2$ & $\mathrm{n} / \mathrm{a}$ & 0 & $\mathrm{n} / \mathrm{a}$ & 0.0 \\
\hline & MC & $1,184.7$ & $\mathrm{n} / \mathrm{a}$ & 766 & $\mathrm{n} / \mathrm{a}$ & 70.8 \\
\hline & VC & $1,272.4$ & $\mathrm{n} / \mathrm{a}$ & 677 & $\mathrm{n} / \mathrm{a}$ & 70.7 \\
\hline & MP & $1,949.0$ & $\mathrm{n} / \mathrm{a}$ & 0 & $\mathrm{n} / \mathrm{a}$ & 70.7 \\
\hline & VP & $1,949.8$ & $\mathrm{n} / \mathrm{a}$ & 0 & $\mathrm{n} / \mathrm{a}$ & 70.7 \\
\hline
\end{tabular}




\section{Chemical analyses}

All frozen samples were transported in a chiller with frozen elements from the two respective trial locations (SSE: Laboratory of Entomology, Wageningen, the Netherlands; LSE: Protix, Dongen, the Netherlands) to Wageningen Food Safety Research (WFSR), Wageningen, the Netherlands, for chemical analyses. For the analysis of contaminants, left-over plastic was as much as possible removed from the samples. Then, the samples were weighed, freeze-dried and re-weighed to determine their dry matter content. The samples were freeze-dried using a Revo ${ }^{\oplus}$ Pro Freeze Dryer (Millrock Technology, Kingston, NY, USA) until a moisture content of $\sim 1-2 \%$ was achieved.

The larval samples of both SSE and LSE, as well as the homogenised feed substrate (HF) and RM samples of the SSE, were analysed for the presence of four heavy metals (Cd, lead; $\mathrm{Pb}$, mercury; $\mathrm{Hg}$ and arsenic; As), dioxins and PCBs, polycyclic aromatic hydrocarbons (PAHs) and mineral oils. All chemicals used were obtained from Actu-All Chemicals (Oss, the Netherlands) and were of persistent environmental contaminants grade. The quality in the analyses was assured by the use of blanks and spiked samples in each sequence. In addition, for all analyses participation in proficiency tests was done on a regular basis.

\section{Heavy metals}

Samples were pre-treated using acid digestion with a microwave oven (MARS express, CEM Corporation, Matthews, NC, USA). For the microwave digestion, $0.8 \mathrm{~g}$ of the sample was mixed with $10 \mathrm{ml}$ concentrated nitric acid (69\% Instra-analysed nitric acid, J.T. Baker, Phillipsburg, NJ, USA) and heated in a microwave oven to a temperature of $210{ }^{\circ} \mathrm{C}$. The digests were quantitatively transferred to $50 \mathrm{ml}$ polypropylene centrifuge tubes (Greiner Bio-One, Frickenhausen, Germany) and diluted with de-ionised water to a final volume of $50 \mathrm{ml}$. The determination of $\mathrm{Cd}, \mathrm{Pb}$ and As concentration was done using an Electrothermal atomic absorption spectrophotometer (ETAAS, Analyst 800, Perkin Elmer, Waltham, MA, USA), equipped with a graphite furnace and Zeeman background correction system). $\mathrm{Cd}, \mathrm{Pb}$ and As were measured at wavelengths of 228.8, 283.3 and $193.7 \mathrm{~nm}$ respectively. To improve the analytical measurements a $0.1 \% \mathrm{Pd}$ and $0.12 \% \mathrm{Mg}\left(\mathrm{NO}_{3}\right)_{2}$ matrix modifier was used. $\mathrm{Hg}$ concentrations were determined using cold vapor atomic fluorescence spectroscopy (CVAFS, Mercur, Analytik Jena, Jena, Germany). Ionic Hg is reduced to gaseous elemental $\mathrm{Hg}$ using tin (II) chloride. $\mathrm{Hg}$ atoms are excited using a $\mathrm{Hg}$ lamp at a wavelength of $253.7 \mathrm{~nm}$ and subsequent fluorescence is detected at the same wavelength. The limits of quantification (LOQs) were $0.007 \mathrm{mg} / \mathrm{kg}$ for $\mathrm{Cd}, 0.028 \mathrm{mg} / \mathrm{kg}$ for $\mathrm{Pb}, 0.062 \mathrm{mg} / \mathrm{kg}$ for As and $0.02 \mathrm{mg} / \mathrm{kg}$ for $\mathrm{Hg}$.

\section{Dioxins and PCBs}

For the analysis of dioxins and PCBs, $2.5 \mathrm{~g}$ of sample was mixed with diatomaceous earth and spiked with $50 \mathrm{pg}{ }^{13} \mathrm{C}_{12}$ dioxins, ${ }^{13} \mathrm{C}_{12}$ furans and ${ }^{13} \mathrm{C}_{12}$ non-ortho-PCBs (EDF5581, Cambridge Isotope Laboratories (CIL), Tewksbury, MA, USA) and $1000 \mathrm{pg}$ of ${ }^{13} \mathrm{C}_{12}$ mono-ortho and ${ }^{13} \mathrm{C}_{12}$ ndl-PCBs (EC-5582, CIL). Subsequently, the samples were transferred to a $33 \mathrm{ml}$ cell containing two cellulose filters and extracted by Accelerated Solvent Extraction (ASE, Thermo Fisher Dionex, Sunnyvale, CA, USA). The samples were extracted 3 times for $15 \mathrm{~min}$. with toluene:ethanol (9:1, $\mathrm{v} / \mathrm{v}$ ) at $100{ }^{\circ} \mathrm{C}, 1,500 \mathrm{PSI}$ and a flush volume of $100 \%$. The extract was filtered over a funnel with anhydrous sodium sulphate and the solvent evaporated in a rotorvapor to approximately $2 \mathrm{ml}$. The residue was reconstituted in $20 \mathrm{ml}$ hexane and spiked with $50 \mathrm{pg}{ }^{13} \mathrm{C}_{12}$ 1368-TCDD (ED-4198, CIL) to evaluate the purification recovery. The mixture was homogenised and introduced on an automated purification system (PowerPrep $^{\text {тm }}$, FMS Inc., Waltham, MA, USA). In this system, the extracts were purified on four columns containing respectively acid silica, neutral silica, basic silica, basic alumina and activated carbon/celite. For the elution of the columns, several solvents and mixtures were used, i.e. respectively hexane, hexane/dichloromethane $(1: 1$, $\mathrm{v} / \mathrm{v})$, ethyl acetate/toluene $(1: 1, \mathrm{v} / \mathrm{v})$ and toluene. From this purification two fractions were obtained containing monoortho and ndl-PCBs in hexane:dichloromethane (1:1, v/v) and dioxins and non-ortho PCBs in toluene. The volume of the final extracts was reduced to $0.5 \mathrm{ml}$ using an automated evaporation system (TurboVap, Biotage, Uppsala, Sweden) with fixed endpoint of $0.5 \mathrm{ml}$. To the mono-ortho and ndlPCB $1 \mathrm{ml}$ iso-octane was added and re-evaporated till 0.5 $\mathrm{ml}$. These extracts were analysed by GC-HRMS (Autospec, Waters, Manchester, UK) equipped with an Agilent 6890 GC (Santa Clara, CA, USA), a combi PAL autosampler from CTC (Zwingen, Switzerland), a split/splitless injector (S/S), a CIS-3 programmed temperature vaporisation injector (PTV) from Gerstel (Mülheim an der Ruhr, Germany) with $\mathrm{CO}_{2}$ cryogenic cooling and a J\&W DB5-MS $60 \mathrm{~m} \times 0.25$ $\mathrm{mm} \times 0.25 \mu \mathrm{m}$ column (Agilent) (Ten Dam et al., 2016) . Data was processed using Masslynx Targetlyn ${ }^{\mathrm{TM}}$ software (Waters) and all results were corrected for the recovery of the corresponding ${ }^{13} \mathrm{C}_{12}$ internal standard.

Results for dioxins and PCBs are reported using the toxic equivalency (TEQ) system. The sums of different dioxin and $\mathrm{PCB}$ congeners are calculated by multiplying the concentration of each compound by its toxic equivalent factor (TEF) value, using WHO2005 TEF values. This TEF is an estimation of the congener's relative toxicity, in relation to the dioxin 2,3,7,8-TCDD (Van den Berg et al., 2006). Focus in this study was on those total TEQ values for which legal limits have been implemented in EU legislation; dioxins [sum of polychlorinated dibenzopara-dioxins (PCDDs) and polychlorinated dibenzofurans 
(PCDFs); mono-ortho PCBs: sum of dioxins and dioxinlike PCBs (sum of polychlorinated dibenzo-para-dioxins (PCDDs), polychlorinated dibenzofurans (PCDFs) and polychlorinated biphenyls (PCBs); and non-dioxin-like PCBs (sum of PCB 28, PCB 52, PCB 101, PCB 138, PCB 153 and PCB 180 (ICES-6) (Directive 2002/32/EC; EC, 2002).

\section{Polycyclic aromatic hydrocarbon}

For the analysis of PAH (EU15+1), $2 \mathrm{~g}$ of sample was mixed with diatomaceous earth and spiked with $6 \mathrm{ng}{ }^{13} \mathrm{C}_{\mathrm{x}} \mathrm{PAH}$ (ES-4087, CLM-9729-1.2, CLM-9863, CLM-9167, CLM9499, CLM-3774-A and CLM-3835-1.2, CIL). Subsequently, the samples were transferred to a $33 \mathrm{ml}$ cell containing two cellulose filters and extracted by Accelerated Solvent Extraction (ASE, Thermo Fisher Dionex). The samples were extracted 3 times for $5 \mathrm{~min}$. with hexane:acetone (1:1, $\mathrm{v} / \mathrm{v})$ at $100{ }^{\circ} \mathrm{C}, 1,500 \mathrm{PSI}$ and a flush volume of $100 \%$. The extract was filtered over a funnel with anhydrous sodium sulphate and the solvent evaporated in a rotatory evaporator to approximately $2 \mathrm{ml}$. The residue was reconstituted in $15 \mathrm{ml}$ ethylacetate:cyclohexane 1:1 and introduced on a gel permeation chromotography system. This system consisted of a 307 HPLC pump, GX-271 injector, 402 syringe pumpcontrolled by Trilution LC 2.1 software all from Gilson (Randwijk, the Netherlands) and a $60 \mathrm{~cm} \times 2.5 \mathrm{~cm}$ i.d. glass chromatography column (Spectrum by Omnilabo, Breda, the Netherlands) filled with BioBeads SX3 200-400 mesh (Bio-rad, Hercules, CA, USA). Of the sample extract, 12.5 $\mathrm{ml}$ was introduced at a flow rate of $2 \mathrm{ml} / \mathrm{min}$. After $10.5 \mathrm{~min}$ the flow was raised to $5 \mathrm{ml} / \mathrm{min}$ and the fraction containing the PAH was collected between 35 and $97 \mathrm{~min}$. The extract was evaporated till $0.5 \mathrm{ml}$ using a TurboVap after which the last $0.5 \mathrm{ml}$ was evaporated till just dryness in a Pierce reacti-Therm ${ }^{\mathrm{Tw}}$ nitrogen evaporator (Thermo Scientific, Waltham, MA, USA). The residues were reconstituted in $0.5 \mathrm{ml}$ hexane and additionally purified over $1 \mathrm{~g}$ aluminium oxide 0.063-0.200 mesh (Merck, Kenilworth, NJ, USA) columns deactivated with $14 \%$ demineralised water. The columns were conditioned with $2 \mathrm{ml}$ hexane. Subsequently the sample was applied to the column and eluted with an additional $3.5 \mathrm{ml}$ hexane. The extract was again evaporated till just dryness and reconstituted in $0.1 \mathrm{ml}$ iso-octane containing $0.1 \mathrm{ng} / \mathrm{ml}$ Perlylene $\mathrm{D}_{12}$ (DLM-366-1.2, CIL). The extracts were like dioxins and PCBs analysed by GCHRMS. For PAH analysis the system was equipped with a PAH select GC column (Agilent) and $1 \mu \mathrm{l}$ was injected on a $\mathrm{S} / \mathrm{S}$ injector in splitless mode at $300^{\circ} \mathrm{C}$, at a flow rate of $2 \mathrm{ml} / \mathrm{min}$ using helium as carrier gas. The purge time was set at $2 \mathrm{~min}$. The oven temperature gradient consisted of 4 ramps and isotherm periods; 1 : initially the oven was set initially at $70^{\circ} \mathrm{C}$ for $0.7 \mathrm{~min}$ after which the temperature was increased with $25^{\circ} \mathrm{C} / \mathrm{min}$ to $180^{\circ} \mathrm{C}$; 2 : after $3 \mathrm{~min}$ isotherm the oven was ramped with $3^{\circ} \mathrm{C} / \mathrm{min}$ to $230^{\circ} \mathrm{C}$; 3 : after $7 \mathrm{~min}$ isotherm the oven was ramped with $28^{\circ} \mathrm{C} / \mathrm{min}$ to $280^{\circ} \mathrm{C}$; 4 : after $10 \mathrm{~min}$ isotherm the oven was ramped with $14{ }^{\circ} \mathrm{C} / \mathrm{min}$ to $340^{\circ} \mathrm{C}$ which was remained isotherm for 10 more minutes. The HRMS was operated in the electron ionisation negative mode at 12,000 resolution at $10 \%$ peak height and was tuned and calibrated prior to each sequence. For each PAH the two most abundant mono-isotopic ions were monitored of which the most abundant ion was used for quantification and the second ion for qualification. A calibration curve was measured in the range of 0.05$0.25 \mathrm{ng} / \mathrm{ml}$ using a custom made native PAH mixture of Chiron (Trondheim, Norway) and the previously described internal standards. Data was processed using Masslynx Targetlyn $x^{\text {Tix }}$ software (Waters) and all results were corrected for recovery of the corresponding ${ }^{13} \mathrm{C}_{\mathrm{x}}$ internal standard except for dibenzo(a,h)pyrene which was corrected for ${ }^{13} \mathrm{C}_{12}$ dibenzo(a,i)pyrene.

\section{Mineral oil hydrocarbons}

The analysis of mineral oil focused on $\mathrm{C}_{10}-\mathrm{C}_{40}$ excluding natural substances like uneven alkanes $\left(\mathrm{C}_{25}\right.$ till $\left.\mathrm{C}_{33}\right)$, sterols and free fatty acids. For this analysis $0.5 \mathrm{~g}$ of sample was spiked with $250 \mathrm{ng} n$-decane $\mathrm{D}_{22}, \mathrm{n}$-dodecane $\mathrm{D}_{26}$, n-eicosane $\mathrm{D}_{42}$ and $\mathrm{n}$-hexatricontane $\mathrm{D}_{74}$ (DLM-133-0, DLM-338-0, DLM-2208-0 and DLM-2634-0, CIL) and extracted with $5 \mathrm{ml}$ hexane in an ultrasonic bath (Branson Ultrasonics, Danbury, CT, USA). After centrifugation 4 $\mathrm{ml}$ of the extract was transferred into a reagent tube and evaporated till $0.5 \mathrm{ml}$ in a TurboVap evaporation device with $0.5 \mathrm{ml}$ endpoint. The extracts were purified over 3.5 g silica column (glass) conditioned with $10 \mathrm{ml}$ hexane and eluted with $12.5 \mathrm{ml}$ hexane. To each of the purified extracts $10 \mathrm{ng}$ 1,2,3,4-tetrachloornaphtalene was added and the extracts were concentrated by evaporation till 250 $\mu \mathrm{l}$ using a Pierce reacti-Therm ${ }^{\mathrm{mw}}$ nitrogen evaporator. The extracts were analysed on a Trace ${ }^{\mathrm{Tm}} \mathrm{GC}-\mathrm{MS}$ (Thermo Fisher Scientific) equipped with a Rxi-5Sil MS fused silica column (Restek, Bellefonte, PA, USA), a PAL autosampler (CTC) and $\mathrm{X}$-calibur controlling and data processing software (Thermo Fisher Scientific). The injected volume was $2 \mu \mathrm{l}$ in cold splitless mode at $50^{\circ} \mathrm{C}$ and a splitless time of $2 \mathrm{~min}$. The injector temperature was ramped with $10^{\circ} \mathrm{C} / \mathrm{min}$ after 0.1 min till $280^{\circ} \mathrm{C}$ for transfer of the analytes to the GC column. After $30 \mathrm{~min}$ the injector temperature was raised to $320^{\circ} \mathrm{C}$. The helium gas flow was $1.3 \mathrm{ml} / \mathrm{min}$, and the oven was set to start at $45{ }^{\circ} \mathrm{C}$. After $2 \mathrm{~min}$ the oven was ramped with $10{ }^{\circ} \mathrm{C} / \mathrm{min}$ till $300{ }^{\circ} \mathrm{C}$ and set to remain at this temperature for $15 \mathrm{~min}$. The MS was set in electron ionisation negative mode and full scans were recorded ranging from $\mathrm{m} / \mathrm{z} 50$ to $\mathrm{m} / \mathrm{z} 700$ while also recording single ions of $\mathrm{m} / \mathrm{z} 85,95,97$, $99,109,111,113,114,123,125,127,130$ and 266 for 0.02 sec each. A calibration curve was measured in the range of 10-500 $\mu \mathrm{g} / \mathrm{ml}$ using a mineral oil RIVM-NMi-001 (VSL B.V., Delft, the Netherlands) and the previously described internal standards. The contents of natural substances were determined from $\mathrm{m} / \mathrm{z} 113$. The uncorrected mineral oil contents were determined from $\mathrm{m} / \mathrm{z}$ 85, 99, 113 and 
127. The corrected mineral oil amounts were consequently determined by deducting the results for natural substances from the uncorrected mineral oil contents. The results were corrected for internal standard (n-decane $\mathrm{D}_{22}$ ). The LOQ was $50 \mathrm{mg} / \mathrm{kg}$.

\section{Data analyses}

Data for the SSE ( $n=3$ per treatment) are reported by providing the mean and standard deviation (SD) of the measured concentrations. For the LSE $(n=2)$, the mean is provided.

The bioaccumulation factor (BAF) was adapted from Walker (1990) and calculated on a dry matter (DM) basis, per contaminant, using SSE data, as: BAF = concentration BSF larvae (DM) / concentration in the HF at the start of the experiment (DM). A BAF greater than 1 indicates bioaccumulation of the contaminant from the substrate into the BSF larvae. If larval concentrations $>$ LOQ, but concentrations in the $\mathrm{HF}$ are $<\mathrm{LOQ}$; then the corresponding BAFs must be $>1([\mathrm{X}>\mathrm{LOQ}] /[\mathrm{LOQ}]=[\mathrm{Y}>1])$; because the LOQ was the same for both matrices. However, exact BAF values in these cases cannot be determined.

\section{Compliance with legal limits}

Compliance of BSF larvae and HF was assessed by comparing the concentrations of contaminants to their respective maximum residue limits (MRLs) in the EU. For each category of contaminants, the applicable MRLs for animal feed as laid down in Directive 2002/32/EC on undesirable substances in animal feed are shown in Table 3. No specific MRLs exist for insect products and product descriptions to which MRLs apply are defined in general terms. For heavy metals ( $\mathrm{Cd}, \mathrm{Pb}, \mathrm{As}, \mathrm{Hg}$ ); the MRLs for 'complete feed' were interpreted to be applicable to the substrate. The MRLs for 'feed materials of animal origin' (Cd) or 'feed materials ( $\mathrm{Pb}, \mathrm{As}, \mathrm{Hg}$ ) were interpreted to be applicable to the BSF larvae. For dioxins and PCBs, the MRLs for 'compound feed' and 'feed materials of animal origin (other land animal products)' were interpreted to be applicable to the substrate and larvae, respectively. For dioxins and PCBs, MRLs apply to upper bound (ub) concentrations - which assumes that all concentrations of the different congeners that could not be quantified are equal to the LOQ value. Maximum contents (as presented in Table 3) are relative to a feed with a moisture content of $12 \%$. The concentrations of contaminants were assessed in products in a freeze-dried state with an estimated moisture content of $\sim 1-2 \%$. As such, found concentrations were recalculated by decreasing them by $10 \%$ before comparing these levels to the respective MRLs.

No MRLs apply to feed products for mineral oil hydrocarbons and PAHs. For food products, maximum levels have been set for the sum of four indicator $\mathrm{PAH}$ (PAH4)s: benzo(a)pyrene, benz(a)anthracene, benzo(b) fluoranthene and chrysene (Section 6, Annex of Regulation (EC) No 1881/2006 setting maximum levels for certain contaminants in foodstuffs) - which are used as marker compounds for 16 priority PAHs (PAH16) (EFSA, 2008). The lowest legal limits for these four indicator PAHs is $1.0 \mu \mathrm{g} / \mathrm{kg}$ in e.g. infant formulae and dietary foods for medical purposes intended especially for infants; the highest maximum level is $50.0 \mu \mathrm{g} / \mathrm{kg}$ in dried herbs and spices.

EFSA has indicated in a scientific opinion that 'migration from recycled paper packaging could contribute significantly to the total exposure' (EFSA, 2012). According to EFSA,

Table 3. Applicable maximum residue limits (MRLs) for undesirable substances in animal feed as laid down in Directive 2002/32/ EC: maximum content interpreted to be applicable to the substrate and larvae, relative to feed materials with a standard moisture content of $12 \%$.

\begin{tabular}{|c|c|c|}
\hline Undesirable substance & MRL substrate & MRL larvae \\
\hline Cadmium & $0.5 \mathrm{mg} / \mathrm{kg}$ & $2 \mathrm{mg} / \mathrm{kg}$ \\
\hline Lead & $5 \mathrm{mg} / \mathrm{kg}$ & $10 \mathrm{mg} / \mathrm{kg}$ \\
\hline Arsenic & $2 \mathrm{mg} / \mathrm{kg}$ & $2 \mathrm{mg} / \mathrm{kg}$ \\
\hline Mercury & $0.1 \mathrm{mg} / \mathrm{kg}$ & $0.1 \mathrm{mg} / \mathrm{kg}$ \\
\hline $\begin{array}{l}\text { Dioxins [sum of polychlorinated dibenzo-para-dioxins (PCDDs) and polychlorinated } \\
\text { dibenzofurans (PCDFs) expressed in WHO toxic equivalents, using the WHO- } \\
\text { TEFs (toxic equivalency factors, 2005) }\end{array}$ & $\begin{array}{l}0.75 \mathrm{ng} \text { WHO-PCDD/ } \\
\mathrm{F}-\mathrm{TEQ} / \mathrm{kg}\end{array}$ & $\begin{array}{l}0.75 \mathrm{ng} \text { WHO-PCDD/ } \\
\text { F-TEQ/kg }\end{array}$ \\
\hline $\begin{array}{l}\text { Sum of dioxins and dioxin-like PCBs (sum of polychlorinated dibenzo-para-dioxins } \\
\text { (PCDDs), polychlorinated dibenzofurans (PCDFs) and polychlorinated biphenyls } \\
\text { (PCBs) expressed in WHO toxic equivalents, using the WHO-TEFs (toxic } \\
\text { equivalency factors), 2005) }\end{array}$ & $\begin{array}{l}1.5 \mathrm{ng} \text { WHO-PCDD/ } \\
\text { F-PCB-TEQ/kg }\end{array}$ & $\begin{array}{l}1.25 \mathrm{ng} \text { WHO-PCDD/ } \\
\text { F-PCB-TEQ/kg }\end{array}$ \\
\hline $\begin{array}{l}\text { Non-dioxin-like PCBs (sum of PCB 28, PCB 52, PCB 101, PCB 138, PCB } 153 \text { and } \\
\text { PCB } 180 \text { (ICES-6) }\end{array}$ & $10 \mu \mathrm{g} / \mathrm{kg}$ & $10 \mu \mathrm{g} / \mathrm{kg}$ \\
\hline
\end{tabular}


some types of mineral oil hydrocarbons $(\mathrm{MOH})$ may act as genotoxic carcinogens ('aromatic $\mathrm{MOH}$ '); while other types may accumulate and cause liver damage ('saturated $\mathrm{MOH}$ '). Due to the high complexity of $\mathrm{MOH}$ mixtures relevant to dietary exposure, it is difficult to perform a full risk assessment (EFSA, 2012, 2019). There are no legal limits for $\mathrm{MOH}$ in the EU (Regulation (EU) No 37/2010; EC, 2010). However, based on Good Manufacturing Practices from feed industry, the rejection limit for hydrocarbons $\mathrm{C}_{10}-\mathrm{C}_{40}$ varies from $400 \mathrm{mg} / \mathrm{kg}$ for animal fat to 3,000 mg/ $\mathrm{kg}$ for crude fish oil and vegetable fatty acids (GMP+, 2018).

\section{Statistical analysis}

For the statistical analyses, the software GraphPad Prism 5 for Microsoft Windows (version 5.02, GraphPad Software, Inc., San Diego, CA, USA) was used. Differences between treatments were statistically analysed by performing a oneway analysis of variance (ANOVA), followed by Bonferroni's Multiple Comparison Test $(\alpha=0.05)$.

\section{Results}

\section{Survival and growth}

The total weight and number of surviving BSF larvae on day seven (D7) of the larvae in the SSE, and total weight of the larvae in the LSE are shown in Table 4. For both total weight and survival of the larvae in the SSE, there were no significant differences between the treatments $(P>0.05)$. However, in the SSE, differences in the individual larval weight were significant $(P \leq 0.0001)$ resulting from the larval weight in the two treatments containing paperboard carton (MC, VC) being lower than in the two treatments containing plastic (MP, VP). Between D6 and D7 (i.e. the 'starvation period') in the LSE, there was no observed change in the number of larvae, and only a slight reduction in biomass
(3.4 $\pm 0.3 \%$ reduction compared to D6, as a combined mean for all tested replicates). The total weight of the larvae in the two treatments in the LSE containing paperboard carton (MC, VC) was lower than in the two treatments containing plastic (MP, VP); this was in agreement with the results of the individual larval weight in the SSE.

\section{Heavy metals}

For almost all samples of all matrices in the SSE, concentrations of $\mathrm{As}$ and $\mathrm{Hg}$ were below their respective LOQs of 0.062 and $0.02 \mathrm{mg} / \mathrm{kg}$. The exceptions were two residual material samples in the VC treatment that contained As concentrations slightly above the LOQ (0.062), at $0.067 \mathrm{mg} / \mathrm{kg}$.

Results for the presence of $\mathrm{Cd}$ and $\mathrm{Pb}$ in the larvae, $\mathrm{HF}$, and residual material in the SSE are presented in Table 5. There were significant differences in $\mathrm{Cd}$ concentrations between the treatments in the SSE in all three matrices (larvae, HF, residual material) $(P \leq 0.0001)$. In all cases, this was due to the Cd concentrations in the control treatments in the SSE being higher than in the other experimental treatments. For instance, the mean Cd concentration in the control residual material was more than twelve times the mean concentration in the other treatments. In case of the HF, the $\mathrm{Cd}$ concentrations in the treatments containing plastic (MP, VP) were in turn also higher than the treatments containing paperboard carton $(\mathrm{MC}, \mathrm{VC})$. For $\mathrm{Pb}$ also, the concentrations in the control samples of larvae $(P \leq 0.05)$ and the residual material $(P \leq 0.01)$ were significantly higher than in the other treatments. Both in the SSE and LSE, the concentrations of all four heavy metals in the HF and BSF larvae were below their respective MRL.

Because concentrations in the HF were $<$ LOQ for As, $\mathrm{Hg}$, and $\mathrm{Pb}$, the BAF could not be calculated for these three

Table 4. Observed total weight and survival of larvae (based on $n=300$ on day 1), and calculated individual weight of the larvae (total weight/number of larvae) on day seven of the small-scale experiment (SSE), and total weight of larvae on day seven of the large-scale experiment (LSE). ${ }^{1}$

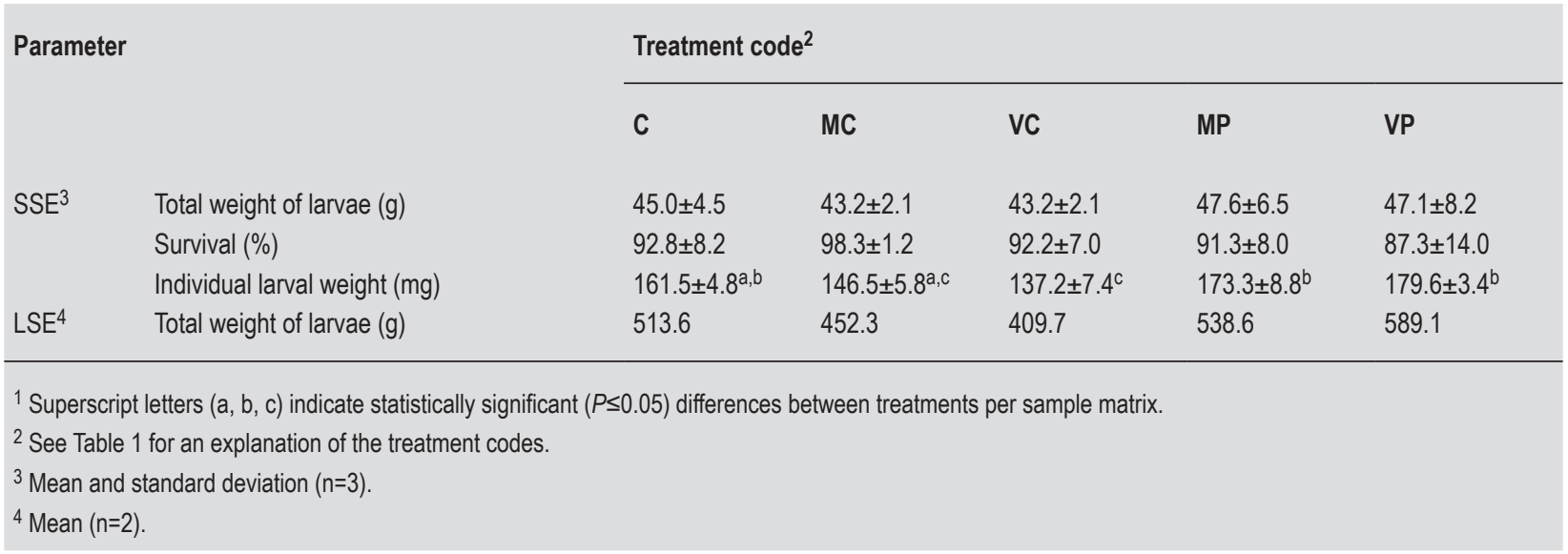


Table 5. Concentrations of cadmium (Cd) and lead (Pb) in black soldier fly (BSF)larvae, residual materials (RM), and homogenised feed substrate (HF) in the small-scale experiment. ${ }^{1}$

\begin{tabular}{|c|c|c|c|}
\hline Sample & Treatment code ${ }^{2}$ & $\mathrm{Cd}(\mathrm{mg} / \mathrm{kg})$ & $\mathrm{Pb}$ (mg/kg) \\
\hline \multirow[t]{5}{*}{ BSF larvae } & C & $0.548 \pm 0.038^{a}$ & $0.185 \pm 0.042^{a}$ \\
\hline & MC & $0.272 \pm 0.012^{b}$ & $0.070 \pm 0.008^{b}$ \\
\hline & VC & $0.286 \pm 0.012^{b}$ & $0.079 \pm 0.006^{b}$ \\
\hline & MP & $0.326 \pm 0.030^{b}$ & $0.060 \pm 0.012^{b}$ \\
\hline & VP & $0.272 \pm 0.052^{b}$ & $0.088 \pm 0.067^{a, b}$ \\
\hline \multirow[t]{5}{*}{ RM } & C & $0.142 \pm 0.019^{a}$ & $0.295 \pm 0.151^{a}$ \\
\hline & MC & $<\operatorname{LOQ}(0.007)^{b}$ & $0.081 \pm 0.019^{b}$ \\
\hline & VC & $0.007^{3}$ & $0.264 \pm 0.041^{a, b}$ \\
\hline & MP & $0.010 \pm 0.001^{b}$ & $0.067 \pm 0.010^{b}$ \\
\hline & VP & $0.011 \pm 0.003^{b}$ & $0.087 \pm 0.012^{b}$ \\
\hline \multirow[t]{5}{*}{ HF } & C & $0.064 \pm 0^{\mathrm{a}}$ & $<\operatorname{LOQ}(0.1)$ \\
\hline & MC & $0.018 \pm 0.001^{b}$ & $<\operatorname{LOQ}(0.028)$ \\
\hline & VC & $0.014 \pm 0.001^{b}$ & $<\operatorname{LOQ}(0.028)$ \\
\hline & MP & $0.042 \pm 0.002^{c}$ & $<\operatorname{LOQ}(0.028)$ \\
\hline & VP & $0.039 \pm 0.003^{c}$ & $<\operatorname{LOQ}(0.028)$ \\
\hline
\end{tabular}

heavy metals. BAFs for $\mathrm{Cd}$ are shown in Figure 1. Differences in BAF values for $\mathrm{Cd}$ were significant $(P \leq 0.0001)$; this was due to the BAF values of both treatments containing paperboard carton $(\mathrm{MC}$ and $\mathrm{VC})$ being higher than the control and the two treatments with plastic (MP, VP). The mean $\mathrm{BAF}$ value for $\mathrm{Cd}$ in the $\mathrm{VC}$ treatment was more than twice as high $(20.0 \pm 1.3)$ as in the control $(8.6 \pm 0.6)$, MP (7.7 \pm 0.9$)$, and VP treatments $(7.1 \pm 1.9)$.

The LSE results largely mirrored the SSE results; concentrations of As and $\mathrm{Hg}$ in the larvae in the LSE were below their respective LOQs of, respectively, 0.062 and $0.02 \mathrm{mg} / \mathrm{kg}$, and larval concentrations of $\mathrm{Cd}$ and $\mathrm{Pb}$ were highest in the control treatments. Results for $\mathrm{Cd}$ and $\mathrm{Pb}$ in the LSE are shown in Table 6.

\section{Mineral oil hydrocarbons}

Results for the concentrations of mineral oil hydrocarbons in the larvae, residual material, and HF in the SSE; calculated BAF values in the SSE; and concentrations in the larvae in the LSE, are presented in Table 7. In the SSE, there were no significant differences in concentrations in the larvae between the treatments $(P>0.05)$. For the residual material and HF in the SSE, these differences were significant $(P \leq 0.001$ for both matrices) due to the concentrations in the control being lower than for the other treatments. Differences in BAF values between the four treatments (MC, VC, MP, VP) in the SSE were small.

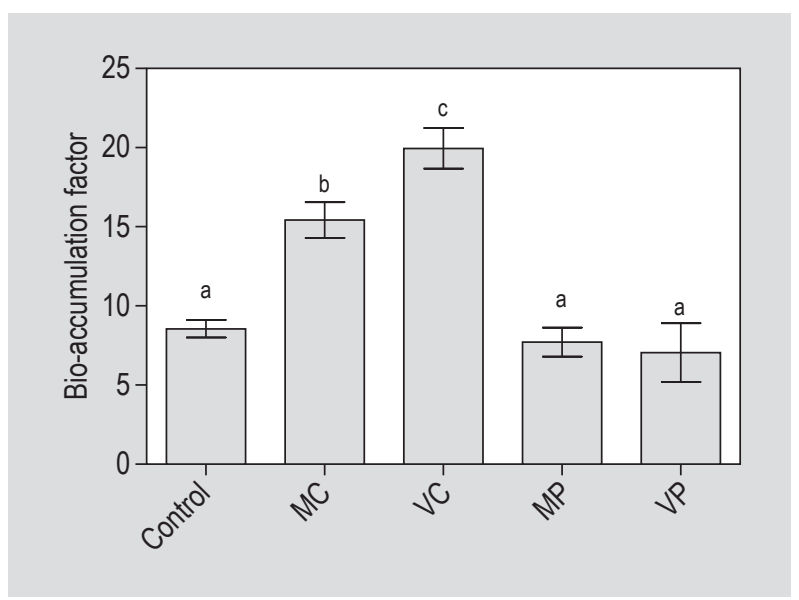

Figure 1. Bioaccumulation factor (BAF) for Cadmium in the small-scale experiment. Different letters $(a, b, c)$ indicate statistically significant $(P \leq 0.05)$ differences between treatments. Mean and standard deviation, $\mathrm{n}=3$.

Because the concentration in the control HF in the SSE was $<\mathrm{LOQ}(50 \mathrm{mg} / \mathrm{kg})$, no exact BAF could be calculated. However, the concentrations in the control larvae were similar to the other treatments, and the LOQ value was approximately half of the quantified concentrations in the other treatments. Therefore, it can be inferred that the BAF for the control in the SSE would substantially exceed the BAF values of the four other treatments. The larval concentrations in the LSE do not appear to differ 
Table 6. Concentrations of cadmium ( $\mathrm{Cd}$ ) and lead $(\mathrm{Pb})$ in the black soldier fly (BSF) larvae in the large-scale experiment.

\begin{tabular}{|c|c|c|c|}
\hline Sample & Treatment code ${ }^{1}$ & $\mathrm{Cd}$ (mg/kg dry weight) ${ }^{2}$ & $\mathrm{~Pb}$ (mg/kg dry weight) ${ }^{2}$ \\
\hline \multirow[t]{5}{*}{ BSF larvae } & C & 0.398 & 0.083 \\
\hline & MC & 0.086 & 0.042 \\
\hline & VC & 0.106 & 0.057 \\
\hline & MP & 0.092 & $0.040^{3}$ \\
\hline & VP & 0.109 & 0.045 \\
\hline
\end{tabular}

Table 7. Concentrations of mineral oil hydrocarbons in black soldier fly (BSF) larvae, residual materials (RM), and the homogenised feed substrate (HF), and calculated bio-accumulation factor in the small-scale experiment, as well as concentrations in the larvae in the large-scale experiment (LSE). ${ }^{1}$

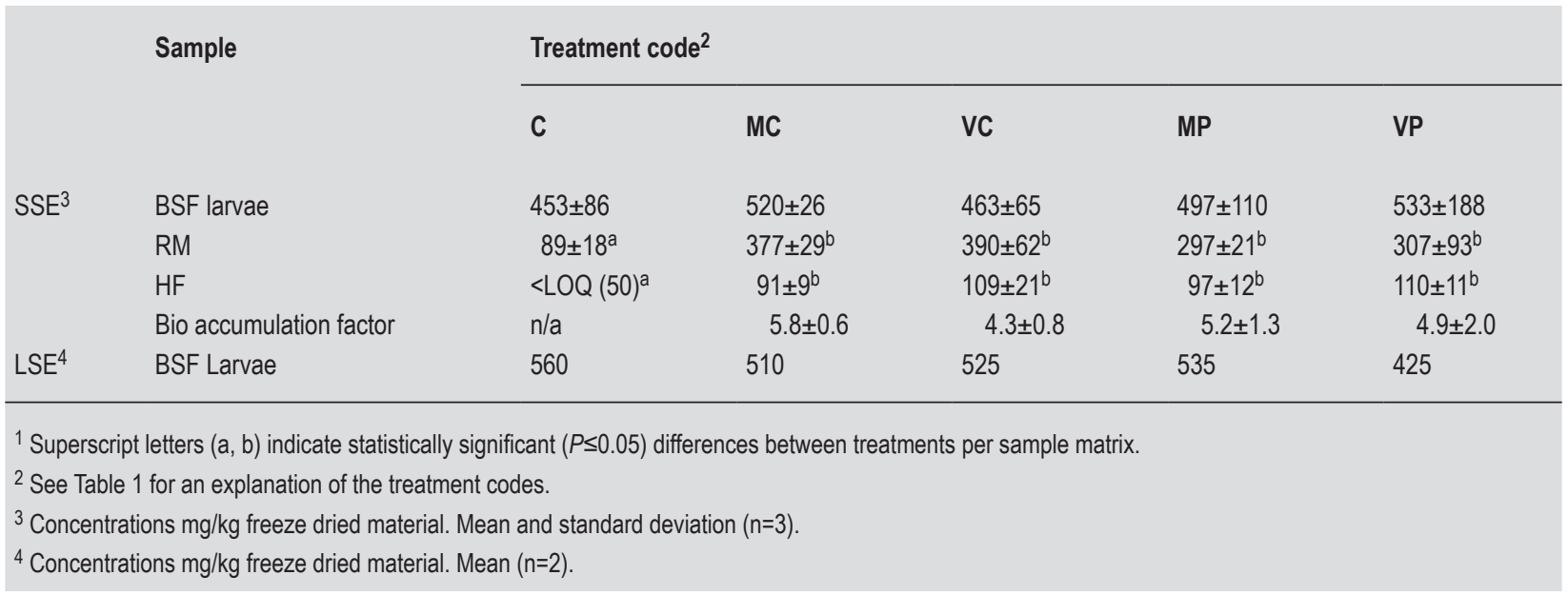

substantially between one another, nor from the larval concentrations in the SSE.

\section{Dioxins and PCBs}

Results for the lower bound (lb) and upper bound (ub) total toxic equivalent (TEQ) values of dioxins, sum of dioxins and dioxin-like (dl-) PCBs, and non-dioxin-like (ndl-) PCBs in larvae, residual material, and HF in the SSE; and for larvae in the LSE are shown in Table 8. For all larvae and HF replicates in both experiments, the ub TEQ values of these three contaminant classes are below their respective applicable MRL. For dioxins, the mean lb TEQ value in the control HF in the SSE was substantially higher than the values for the two plastic treatments $(\mathrm{MP}, \mathrm{VP})(P \leq 0.01)$. However, the ub TEQ values for dioxins in the HF in the SSE were not significantly different $(P>0.05)$. This was due to the comparatively low TEQ values of the individual dioxin congeners that were found to be $>$ LOQ, which thus did not contribute much to the ub TEQ value. For dioxins and
dl-PCBs, there were some significant differences between treatments in the SSE for lb TEQ values in the larvae and residual material $(P \leq 0.05)$, but again these did not result in significantly different ub TEQ values between treatments $(P>0.05)$. For ndl-PCBs, in the residual material in the SSE the ub TEQ value of the MP treatment was substantially higher than for the other treatments $(P \leq 0.01)$.

Concerning bio-accumulation in the SSE, almost all mean BAFs of the values for dioxins, sum of dioxins and dl-PCBS and ndl-PCBs reported in Table 8 were $>1$, showing that accumulation has occurred to some degree - except for the lb TEQ values of dioxins in the control $(0.4 \pm 0.3)$ and $\mathrm{MC}(0.2 \pm 0.2)$ treatments. Despite this lower BAF for the lb TEQ value of dioxins in the MC treatment, a slight but significant difference was observed for the ub TEQ values of dioxins $(P \leq 0.05)$ : the mean for the MC treatment $(2.0 \pm 0.6)$ was higher than those of the control $(1.0 \pm 0.2)$ and MP treatments $(1.0 \pm 0.2)$. Otherwise there were no significant differences in bio-accumulation for the TEQ values of lb 
dioxins, sum of dioxins and dl-PCBS (lb and $\mathrm{ub}$ ) and ndlPCBs (lb and ub) reported in Table 8.

Comparing the results of the TEQ values in the larvae between the LSE and the SSE, there were some differences. For the sum of dioxins and dioxin-like PCBs, and nondioxin-like PCBs the $\mathrm{lb}$ and $\mathrm{ub}$ TEQ values for the MP treatment are consistently and substantially higher than in the other treatments. The mean $\mathrm{lb}$ and $\mathrm{Ub}$ TEQ values of ndl-PCBs for the MP treatment in the LSE being equal $(0.686 \mathrm{ng} \mathrm{TEQ} / \mathrm{kg}$ ) was due to all congeners being $>\mathrm{LOQ}$, thus contributing equally to the $\mathrm{lb}$ and $\mathrm{Ub} T \mathrm{TEQ}$ values.

\section{Polycyclic aromatic hydrocarbon (PAHs)}

Results for the sum of concentrations (PAH4 and PAH16) of polycyclic aromatic hydrocarbon (PAHs) in the larvae, residual material, and HF in the SSE, and for the larvae in the LSE, are presented in Table 9. In the SSE, TEQ values of PAH4 in the larvae were (almost) zero. Both for PAH4 and PAH16 in the larvae, differences were not significant $(P>0.05)$ - but for both PAH4 and PAH16 in the residual material and HF, these differences were significant $(P \leq 0.001)$. For the residual material, this was due to mean PAH4 and PAH16 values of the VC treatment being approximately two (PAH16) to five (PAH4, MP treatment) times higher than that of the other treatments. For the HF also, the mean PAH4 and PAH16 values of the VC treatment

Table 8. Concentrations of dioxins and PCBs in black soldier fly (BSF) larvae, residual materials (RM), and homogenised feed (HF) in the small-scale experiment (SSE), and in the larvae in the large-scale experiment (LSE).

\begin{tabular}{|c|c|c|c|c|c|c|c|}
\hline \multirow[t]{2}{*}{ Sample } & \multirow{2}{*}{$\begin{array}{l}\text { Treatment } \\
\text { code }^{2}\end{array}$} & \multicolumn{2}{|l|}{ Dioxins $^{1}$} & \multicolumn{2}{|c|}{ Sum of dioxins and dioxin-like $\mathrm{PCBs}^{3}$} & \multicolumn{2}{|c|}{ Non-dioxin-like PCBs ${ }^{4}$} \\
\hline & & lb & ub & lb & ub & lb & $u b$ \\
\hline \multicolumn{8}{|l|}{ SSE $^{5}$} \\
\hline \multirow[t]{5}{*}{ BSF larvae } & C & $0.0035 \pm 0.0038$ & $0.258 \pm 0.031$ & $0.099 \pm 0.044^{a}$ & $0.356 \pm 0.025$ & $0.240 \pm 0.325$ & $0.401 \pm 0.0217$ \\
\hline & MC & $0.0005 \pm 0.0006$ & $0.345 \pm 0.086$ & $0.026 \pm 0.026^{a, b}$ & $0.381 \pm 0.105$ & $0.091 \pm 0.132$ & $0.320 \pm 0.109$ \\
\hline & VC & $0.0070 \pm 0.0062$ & $0.291 \pm 0.041$ & $0.034 \pm 0.028^{a, b}$ & $0.327 \pm 0.055$ & $0.000 \pm 0.000$ & $0.284 \pm 0.028$ \\
\hline & MP & $0.0003 \pm 0.0005$ & $0.227 \pm 0.016$ & $0.012 \pm 0.009^{b}$ & $0.250 \pm 0.018$ & $0.030 \pm 0.028$ & $0.284 \pm 0.012$ \\
\hline & VP & $0.0029 \pm 0.0044$ & $0.246 \pm 0.018$ & $0.016 \pm 0.019^{b}$ & $0.281 \pm 0.020$ & $0.059 \pm 0.007$ & $0.288 \pm 0.043$ \\
\hline \multirow[t]{5}{*}{ RM } & C & $0.0005 \pm 0.0004$ & $0.229 \pm 0.014$ & $0.037 \pm 0.042^{a, b}$ & $0.274 \pm 0.027$ & $0.038 \pm 0.038$ & $0.243 \pm 0.022^{a}$ \\
\hline & MC & $0.0037 \pm 0.0013$ & $0.288 \pm 0.064$ & $0.014 \pm 0.015^{a}$ & $0.320 \pm 0.065$ & $0.111 \pm 0.046$ & $0.294 \pm 0.070^{a}$ \\
\hline & VC & $0.0217 \pm 0.0312$ & $0.280 \pm 0.116$ & $0.098 \pm 0.023^{b}$ & $0.360 \pm 0.133$ & $0.026 \pm 0.022$ & $0.273 \pm 0.029^{a}$ \\
\hline & MP & $0.0010 \pm 0.0007$ & $0.241 \pm 0.022$ & $0.029 \pm 0.020^{a, b}$ & $0.281 \pm 0.015$ & $0.023 \pm 0.040$ & $0.536 \pm 0.089^{b}$ \\
\hline & VP & $0.0061 \pm 0.0060$ & $0.220 \pm 0.030$ & $0.046 \pm 0.015^{a, b}$ & $0.260 \pm 0.039$ & $0.107 \pm 0.024$ & $0.286 \pm 0.083^{a}$ \\
\hline \multirow[t]{5}{*}{ HF } & C & $0.0091 \pm 0.0040^{\mathrm{a}}$ & $0.256 \pm 0.046$ & $0.020 \pm 0.020$ & $0.002 \pm 0.001$ & $0.107 \pm 0.016$ & $0.485 \pm 0.344$ \\
\hline & MC & $0.0026 \pm 0.0010^{a, b}$ & $0.173 \pm 0.014$ & $0.027 \pm 0.003$ & $0.198 \pm 0.015$ & $0.111 \pm 0.032$ & $0.261 \pm 0.005$ \\
\hline & VC & $0.0032 \pm 0.0034^{a, b}$ & $0.196 \pm 0.014$ & $0.004 \pm 0.004$ & $0.213 \pm 0.016$ & $0.033 \pm 0.003$ & $0.234 \pm 0.035$ \\
\hline & MP & $0.0003 \pm 0.0002^{b}$ & $0.226 \pm 0.048$ & $0.008 \pm 0.006$ & $0.248 \pm 0.050$ & $0.019^{1}$ & $0.286^{1}$ \\
\hline & VP & $0.0009 \pm 0.0004^{b}$ & $0.199 \pm 0.016$ & $0.028 \pm 0.006$ & $0.228 \pm 0.021$ & $0.074 \pm 0.026$ & $0.250 \pm 0.023$ \\
\hline \multicolumn{8}{|l|}{ LSE $^{6}$} \\
\hline \multirow[t]{5}{*}{ Larvae } & $C$ & 0.0012 & 0.204 & 0.145 & 0.349 & 0.135 & 0.285 \\
\hline & MC & 0.0003 & 0.190 & 0.106 & 0.296 & 0.070 & 0.269 \\
\hline & VC & 0.0055 & 0.271 & 0.085 & 0.353 & 0.090 & 0.286 \\
\hline & MP & 0.0100 & 0.250 & 0.467 & 0.708 & 0.686 & 0.686 \\
\hline & VP & 0.0022 & 0.219 & 0.056 & 0.275 & 0.038 & 0.241 \\
\hline \multicolumn{8}{|c|}{ 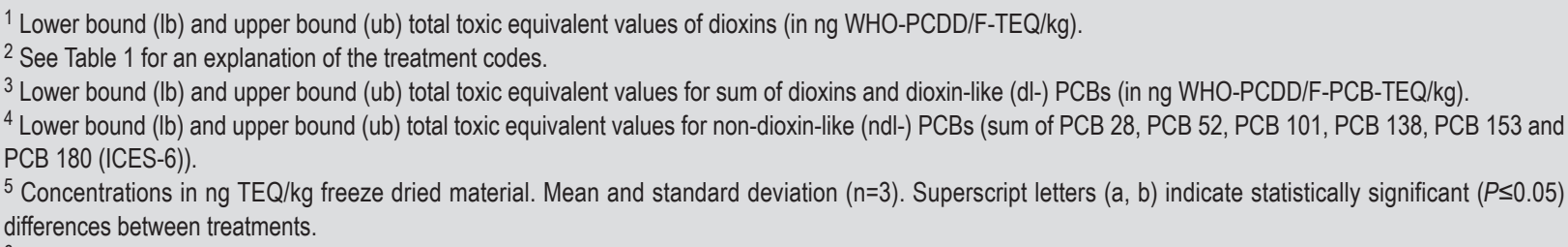 } \\
\hline
\end{tabular}


Table 9. Concentrations of polycyclic aromatic hydrocarbons in black soldier fly (BSF) larvae, residual materials (RM), and the homogenised feed (HF) in the small-scale experiment (SSE), and in the larvae in the large-scale experiment (LSE).

\begin{tabular}{|c|c|c|c|c|}
\hline \multicolumn{2}{|c|}{ Sample } & \multirow{2}{*}{$\begin{array}{l}\text { Treatment } \\
\text { code }^{1} \\
\text { C }\end{array}$} & \multirow{2}{*}{$\begin{array}{l}\text { PAH4 }(\mathrm{lb})^{2} \\
0.00 \pm 0.00\end{array}$} & \multirow{2}{*}{$\begin{array}{l}\text { PAH16 (ub) })^{2} \\
2.13 \pm 0.15\end{array}$} \\
\hline \multirow[t]{15}{*}{$\mathrm{SSE}^{3}$} & Larvae & & & \\
\hline & & $\mathrm{MC}$ & $0.00 \pm 0.00$ & $2.00 \pm 0.00$ \\
\hline & & VC & $0.00 \pm 0.00$ & $2.17 \pm 0.12$ \\
\hline & & MP & $0.00 \pm 0.00$ & $1.87 \pm 0.25$ \\
\hline & & VP & $0.03 \pm 0.06$ & $2.10 \pm 0.00$ \\
\hline & RM & $C$ & $0.83 \pm 0.07$ & $2.58 \pm 0.08$ \\
\hline & & MC & $0.75 \pm 0.08$ & $2.47 \pm 0.07$ \\
\hline & & VC & $2.69 \pm 0.24$ & $5.19 \pm 0.23$ \\
\hline & & MP & $0.54 \pm 0.05$ & $2.08 \pm 0.12$ \\
\hline & & VP & $0.98 \pm 0.90$ & $3.00 \pm 1.29$ \\
\hline & HF & $C$ & $1.74 \pm 0.29$ & $6.62 \pm 1.43$ \\
\hline & & MC & $0.18 \pm 0.10$ & $1.84 \pm 0.19$ \\
\hline & & VC & $2.41 \pm 1.01$ & $4.83 \pm 0.82$ \\
\hline & & MP & $0.58 \pm 0.02$ & $1.88 \pm 0.02$ \\
\hline & & VP & $0.36 \pm 0.01$ & $1.80 \pm 0.07$ \\
\hline \multirow[t]{5}{*}{$\mathrm{LSE}^{4}$} & Larvae & C & 0.05 & 1.60 \\
\hline & & MC & 0.16 & 1.66 \\
\hline & & VC & 0.17 & 1.67 \\
\hline & & MP & 0.33 & 1.82 \\
\hline & & VP & 0.15 & 1.66 \\
\hline \multicolumn{5}{|c|}{$\begin{array}{l}{ }^{2} \text { PAH4 and PAH16: Sum of concentrations of polycyclic aromatic hydrocarbon } \\
\text { (PAHs), respectively PAH4 and PAH16. Lb: lower bound, ub: upper bound. }\end{array}$} \\
\hline \multicolumn{5}{|c|}{$\begin{array}{l}{ }^{3} \text { Concentrations in } \mu \mathrm{g} / \mathrm{kg} \text { freeze dried material. Mean and standard deviation } \\
(n=3) \text {. }\end{array}$} \\
\hline \multicolumn{5}{|c|}{${ }^{4}$ Concentrations in $\mu \mathrm{g} / \mathrm{kg}$ freeze dried material. Mean $(\mathrm{n}=2)$} \\
\hline
\end{tabular}

substantially exceeded those of the other treatments. The mean value of the control treatment was also higher than that of the MC (PAH4 and PAH16), and MP and VP (PAH16) treatments. In the LSE, PAH4 concentrations in the larvae were much higher than in the SSE, while PAH16 values in the LSE larvae were consistently lower than their SSE counterparts.

Since the PAH4 concentrations in the larvae in the SSE were nil compared to the HF values, the corresponding PAH4 BAFs were consequently also nil. BAF values of PAH16 were higher and significantly different from each other $(P \leq 0.001)$; around 1 for the MC (1.1 \pm 0.1$), \mathrm{MP}(1.0 \pm 0.1)$, and VP $(1.2 \pm 0.0)$ treatments; but $<1$ for the control $(0.3 \pm 0.0)$ and $\mathrm{VC}(0.5 \pm 0.1)$ treatments. PAHs thus appear to not, or to a very limited degree, accumulate in BSF larvae.

\section{Discussions}

For all categories of contaminants considered for which legal limits apply $(\mathrm{Cd}, \mathrm{Pb}, \mathrm{As}, \mathrm{Hg}$, dioxins, sum of dioxins and dioxin-like PCBs, non-dioxin-like PCBs) concentrations in the BSF larvae and the homogenised feed substrate were below their respective MRLs. In case of PAH, for which no legal limits for feed apply, the PAH4 TEQ values in the larvae were almost nil, compared to the GMP+ action limit for oils and fats $(160 \mu \mathrm{g} / \mathrm{kg}$, on fat basis $(\mathrm{GMP}+, 2018))$. However, concentrations of mineral oil hydrocarbons $(\mathrm{MOH})$ were relatively high: in all cases the larval concentration exceeded the GMP+ rejection limit for animal fat and vegetable oil $(400 \mathrm{mg} / \mathrm{kg})(\mathrm{GMP}+$, 2018). According to EFSA, 'hydrocarbons are important components of the cuticular lipids of many insects [..] [comprising] between 60 and $90 \%$ of the cuticular lipids of cockroaches and grasshoppers' (EFSA, 2012; Jackson and Blomquist, 1976). The lack of significant differences between the $\mathrm{MOH}$ concentrations found in the control and between the treatments, suggests that these levels are independent of the substrate provided to the insects. More research is therefore recommended on the native content of mineral oil hydrocarbons in insect species reared for food and feed, including BSF larvae.

Differences between treatments in concentrations of contaminants in the larvae were not or only slightly significant. Only for $\mathrm{Cd}$, the concentrations in the control larvae were significantly higher than in the other treatments $(P \leq 0.0001)$. Differences in concentrations between treatments were more often significant for the residual material (Cd, Pb, MOH, ndl-PCBs (ub), PAH4, PAH16), which could imply different excretion or metabolisation patterns depending on the type of substrate or packaging material. There were also some significant differences between treatments in the homogenised feed substrate $(\mathrm{Cd}$, dioxins (lb), PAH4, PAH16), but more research is required to determine the effects of the experimental substrates both with and without packaging materials.

The mean bio-accumulation factor (BAF) of most considered categories of contaminants in the treatments was $>1$ and $<10$ which suggests that accumulation in the larvae has taken place to some degree. For the contaminants that are expressed in total TEQ values (dioxins, PCBs, PAH), some lower and higher mean BAF were found. However, differences between treatments were in most cases not significant due to high variability. For heavy metals and $\mathrm{MOH}$, the highest BAF was observed for Cd in the VC treatment (20.0 \pm 1.3$)$, followed by $\mathrm{Cd}$ in the $\mathrm{MC}$ treatment (15.4 \pm 1.1$)$. High accumulation of Cd in BSF larvae is consistent with previous research, although the $\mathrm{BAF}$ value in this research was higher than the highest BAF value of 9.5 \pm 3.6 , as observed by Van der Fels-Klerx et al. (2016) and $2.9 \pm 0.1$ (in pre-pupae) by Diener et al. (2015). This may 
suggest that the degree of $\mathrm{Cd}$ accumulation is affected by the type of substrate tested. The feed substrate used in this study did contain packaging materials, and when the BSF larvae do not consume the packaging materials at the same rate as the former foodstuffs, this may - at least partly explain the higher BAF. In addition, it may also depend on biological variation between BSF larvae (between studies).

It was observed that the moist environment of the substrate caused the paperboard carton to lose its structural integrity during the course of the experiments. This in turn may have led to some contaminants leaching into the substrate more easily than in the case of the plastic, thereby increasing their bio-availability. For plastic particles; because the BSF larvae to packaging piece size ratio is generally high, the larvae are less likely to ingest whole pieces of the packaging than other species - but more research is required on the potential degradation of plastic by the BSF larvae, in particular by focusing on the impact of different particle sizes.

Comparing the results of the concentrations of the BSF larvae in the LSE to the SSE, no substantial differences were observed for heavy metals, $\mathrm{MOH}$, and dioxins. For the sum of dioxins and dioxin-like PCBs, and non-dioxin-like PCBs in the LSE; the lb and ub TEQ values for the MP treatment are consistently and substantially higher than in the other treatments. This was not the case in the SSE. In the LSE, PAH4 concentrations in the larvae were much higher than in the SSE, while PAH16 values in the LSE larvae were consistently lower than their SSE counterparts. It is unclear what may have caused these differences. It might be that the difference in the number of larvae per replicate in the LSE and SSE played a role, but more research on differences in accumulation patterns depending on the scale of the experiment is needed.

\section{Conclusions and recommendations}

We conclude that BSF larvae can be reared on former food products containing 3-6\% of plastic fragments or paperboard carton packaging materials without negative effects on growth or survival. In addition, all concentrations in the homogenised feed substrate and the larvae did not exceed the respective legal limits in the EU.

Bio-accumulation (BAF) was observed for most tested contaminants, with a very high BAF for $\mathrm{Cd}$ in the vegetarian product with paperboard carton packaging mixed (VC). Bio-accumulation of $\mathrm{Cd}$ from products contaminated with paperboard carton packaging material appears to be higher than for plastic, but no such patterns could be discerned for other contaminants; nor for meat vs vegetarian products.

We recommend continued vigilance by BSF larvae farmers in selecting substrates low in Cd. Although high Cd levels in the substrate do not appear to negatively affect the growth or survival of the BSF larvae, accumulation thereof may lead to feed materials that are exceeding legislative limits. Additional research is recommended on BSF larvae accumulation patterns of the analysed contaminants from other sources than packaging materials present in the substrate. This study was a pilot study using former feedstuffs as substrate for BSF larvae rearing, with promising results. Further research is however warranted, in particular with more different former feedstuffs in each of the various classes, and on different types and particle sizes of packaging materials. Finally, more research is also recommended on assessing the accumulation or transfer of other potential hazards that may be associated with the use of former food products as substrate, such as microbiological hazards.

\section{Acknowledgements}

This study was financed by the Netherlands Ministry of Economic Affairs through the TKI project AF-15200 (Safety of Insects for Feed and Food use). The authors acknowledge the contribution of colleagues from WFSR for the chemical analyses of the contaminants, and Elise Hoek and Hilko Van der Voet for assistance in the statistical analysis of the data presented in this study.

\section{Conflict of interest}

The authors declare no conflict of interest.

\section{Supplementary material}

Supplementary material can be found online at https://doi. org/10.3920/JIFF2020.0024.

Table S1. Details of food products used per treatments: weight of substrate and volume of water provided on day 1 and 3; name(s) of food product; and respective supplier(s) in the small-scale experiment.

Table S2. Details of food products used per treatments: weight of substrate and volume of water provided on day 1 and 3; name(s) of food product; and respective supplier(s) in the large-scale experiment.

\section{References}

\footnotetext{
Advisory Committee on Animal Feedingstuffs (ACAF), 2013. Traces of packaging material in feed derived from former foodstuffs. $60^{\text {th }}$ meeting of ACAF. January 16, 2013. ACAF, London, UK.

Barragan-Fonseca, K.B., Dicke, M. and Van Loon, J.J., 2017. Nutritional value of the black soldier fly (Hermetia illucens L.) and its suitability as animal feed - a review. Journal of Insects as Food and Feed 3(2): 105-120.
} 
Bosch, G., Van der Fels-Klerx, H.J., De Rijk, T.C. and Oonincx, D.G.A.B., 2017. Aflatoxin B1 tolerance and accumulation in black soldier fly larvae (Hermetia illucens) and yellow mealworms (Tenebrio molitor). Toxins 9(6): 185.

Bosch, G., Van Zanten, H.H.E., Zamprogna, A., Veenenbos, M., Meijer, N.P., Van der Fels-Klerx, H.J. and Van Loon, J.J.A., 2019. Conversion of organic resources by black soldier fly larvae: legislation, efficiency and environmental impact. Journal of Cleaner Production 222: 355-363.

Camenzuli, L., Van Dam, R., De Rijk, T.C., Andriessen, R., Van Schelt, J. and Van der Fels-Klerx, H.J., 2018. Tolerance and excretion of the mycotoxins aflatoxin B1, zearalenone, deoxynivalenol, and ochratoxin A by Alphitobius diaperinus and Hermetia illucens from contaminated substrates. Toxins 10(2): 91.

Charlton, A.J., Dickinson, M., Wakefield, M.E., Fitches, E., Kenis, M., Han, R., Zhu, F., Kone, N., Grant, M., Devic, E., Bruggeman, G., Prior, R. and Smith, R., 2015. Exploring the chemical safety of fly larvae as a source of protein for animal feed. Journal of Insects as Food and Feed 1(1): 7-16.

Diener, S., Zurbrügg, C. and Tockner, K., 2015. Bioaccumulation of heavy metals in the black soldier fly, Hermetia illucens and effects on its life cycle. Journal of Insects as Food and Feed 1(4): 261-270.

Ermolaev, E., Lalander, C. and Vinnerås, B., 2019. Greenhouse gas emissions from small-scale fly larvae composting with Hermetia illucens. Waste Management 96: 65-74.

European Commission (EC), 2002. Directive 2002/32/EC of the European Parliament and of the Council of 7 May 2002 on undesirable substances in animal feed - Council statement. Official Journal of the European Union L 140: 10-22. Available at: https:// tinyurl.com/yblr8gfu.

European Commission (EC), 2009. Regulation (EC) No 767/2009 of the European Parliament and of the Council of 13 July 2009 on the placing on the market and use of feed, amending European Parliament and Council Regulation (EC) No 1831/2003 and repealing Council Directive 79/373/EEC, Commission Directive 80/511/EEC, Council Directives 82/471/EEC, 83/228/EEC, 93/74/ EEC, 93/113/EC and 96/25/EC and Commission Decision 2004/217/ EC. Official Journal of the European Union L 229: 1-28. Available at: https://tinyurl.com/y9ze6y4c.

European Commission (EC), 2010. Commission Regulation (EU) No 37/2010 of 22 December 2009 on pharmacologically active substances and their classification regarding maximum residue limits in foodstuffs of animal origin. Official Journal of the European Union L 15: 1-72. Available at: https://tinyurl.com/ycx7jf56.

European Commission (EC), 2013. Commission Regulation (EU) No 68/2013 of 16 January 2013 on the catalogue of feed materials Official Journal of the European Union L 29: 1-64. Available at: https://tinyurl.com/y89kdgbj.

European Food Safety Authority (EFSA) panel on Contaminants in the Food Chain (CONTAM), 2012. Scientific opinion on mineral oil hydrocarbons in food. EFSA Journal 10(6): 2704. https://doi. org/10.2903/j.efsa.2012.2704

European Food Safety Authority (EFSA), 2008. Polycyclic aromatic hydrocarbons in food-scientific opinion of the panel on contaminants in the food chain. EFSA Journal 6(8): 724.
European Food Safety Authority (EFSA), Arcella, D., Baert, K. and Binaglia, M., 2019. Rapid risk assessment on the possible risk for public health due to the contamination of infant formula and follow-on formula by mineral oil aromatic hydrocarbons (MOAH). EFSA Supporting Publication 16(11): 1741. https://doi.org/10.2903/ sp.efsa.2019.EN-1741

GMP+ Feed Certification Scheme, 2018. Specific feed safety limits (version ENL $6^{\text {th }}$ of April 2018). GMP+ International, the Hague, the Netherlands.

Jackson, L.L. and Blomquist, G.L., 1976. Cuticular lipids of insects: VIII. Alkanes of the Mormon cricket Anabrus simplex. Lipids 11:77-79.

Józefiak, D., Józefiak, A., Kierończyk, B., Rawski, M., Świątkiewicz, S., Długosz, J. and Engberg, R.M., 2016. Insects - a natural nutrient source for poultry - a review. Annals of Animal Science 16(2): 297-313.

Lähteenmäki-Uutela, A., Grmelová, N., Hénault-Ethier, L., Deschamps, M.H., Vandenberg, G.W., Zhao, A., Zhang, Y., Yang, B. and Nemane, V., 2017. Insects as food and feed: laws of the European Union, United States, Canada, Mexico, Australia, and China. European Food and Feed Law Review 12(1): 22-36.

Mertenat, A., Diener, S. and Zurbrügg, C., 2019. Black soldier fly biowaste treatment - assessment of global warming potential. Waste Management 84: 173-181.

Nguyen, T.T., Tomberlin, J.K. and Vanlaerhoven, S., 2015. Ability of black soldier fly (Diptera: Stratiomyidae) larvae to recycle food waste. Environmental Entomology 44(2): 406-410.

Oonincx, D.G.A.B., Van Broekhoven, S., Van Huis, A. and Van Loon, J.J.A., 2015. Feed conversion, survival and development, and composition of four insect species on diets composed of food byproducts. PLoS ONE 10(12): e0144601.

Schmitt, E., Belghit, I., Johansen, J., Leushuis, R., Lock, E.J., Melsen, D., Shanmugam, R.K.R., Van Loon, J. and Paul, A., 2019. Growth and safety assessment of feed streams for black soldier fly larvae: a case study with aquaculture sludge. Animals 9(4): 189.

Smetana, S., Palanisamy, M., Mathys, A. and Heinz, V., 2016. Sustainability of insect use for feed and food: life cycle assessment perspective. Journal of Cleaner Production 137: 741-751.

Smetana, S., Schmitt, E. and Mathys, A., 2019. Sustainable use of Hermetia illucens insect biomass for feed and food: attributional and consequential life cycle assessment. Resources, Conservation and Recycling 144: 285-296.

Ten Dam, G., Pussente, I.C., Scholl, G., Eppe, G., Schaechtele, A. and Van Leeuwen, S., 2016. The performance of atmospheric pressure gas chromatography-tandem mass spectrometry compared to gas chromatography - high resolution mass spectrometry for the analysis of polychlorinated dioxins and polychlorinated biphenyls in food and feed samples. Journal of Chromatography A 1477: 76-90. Ten Dam, G., Pussente, I.C., Scholl, G., Eppe, G., Schaechtele, A. and Van Leeuwen, S., 2016. The performance of atmospheric pressure gas chromatography-tandem mass spectrometry compared to gas chromatography - high resolution mass spectrometry for the analysis of polychlorinated dioxins and polychlorinated biphenyls in food and feed samples. Journal of Chromatography A 1477: 76-90. 
Van Broekhoven, S., Gutierrez, J.M., De Rijk, T.C., De Nijs, W.C.M. and Van Loon, J.J.A., 2017. Degradation and excretion of the Fusarium toxin deoxynivalenol by an edible insect, the Yellow mealworm (Tenebrio molitor L.). World Mycotoxin Journal 10(2): 163-169.

Van den Berg, M., Birnbaum, L.S., Denison, M., De Vito, M., Farland, W., Feeley, M., Fiedler, H., Hakansson, H., Hanberg, A., Haws, L., Rose, M., Safe, S., Schrenk, D., Tohyama, C., Tritscher, A., Tuomisto, J., Tsklind, M., Walker, N. and Peterson, R.E., 2006. The 2005 World Health Organization reevaluation of human and mammalian toxic equivalency factors for dioxins and dioxin-like compounds. Toxicological Sciences 93(2): 223-241.

Van der Fels-Klerx, H.J., Camenzuli, L., Van Der Lee, M.K., Oonincx, D.G.A.B., 2016. Uptake of cadmium, lead and arsenic by Tenebrio molitor and Hermetia illucens from contaminated substrates. PLoS ONE 11(11): e0166186.
Van Raamsdonk, L.W.D., Rijk, R., Schouten, G.P.J., Mennes, W., Meijer, G.A.L., Van der Poel, A.F.B., De Jong, J., 2011. RIKILT Report Report 2011.002 - a risk evaluation of traces of packaging materials in former food products intended as feed materials. Available at: https://edepot.wur.nl/171617

Van Raamsdonk, L.W.D., Van der Fels-Klerx, H.J. and De Jong, J., 2017. New feed ingredients: the insect opportunity. Food Additives \& Contaminants: Part A 34(8): 1384-1397.

Walker, C.H., 1990. Persistent pollutants in fish-eating sea birds bioaccumulation, metabolism and effects. Aquatic Toxicology 17(4): 293-324.

Wang, Y.S. and Shelomi, M., 2017. Review of black soldier fly (Hermetia illucens) as animal feed and human food. Foods 6(10): 91. 